\title{
MATA PENCARIAN SEBAGAI MUTUALISME MASYARAKAT PETANI DI DESA SULOBAJA
}

\section{Metildis Nofani}

Universitas Islam Negeri (UIN) Sumatera Utara, Medan, Indonesia

Email: metildisnofani1968042003@gmail.com

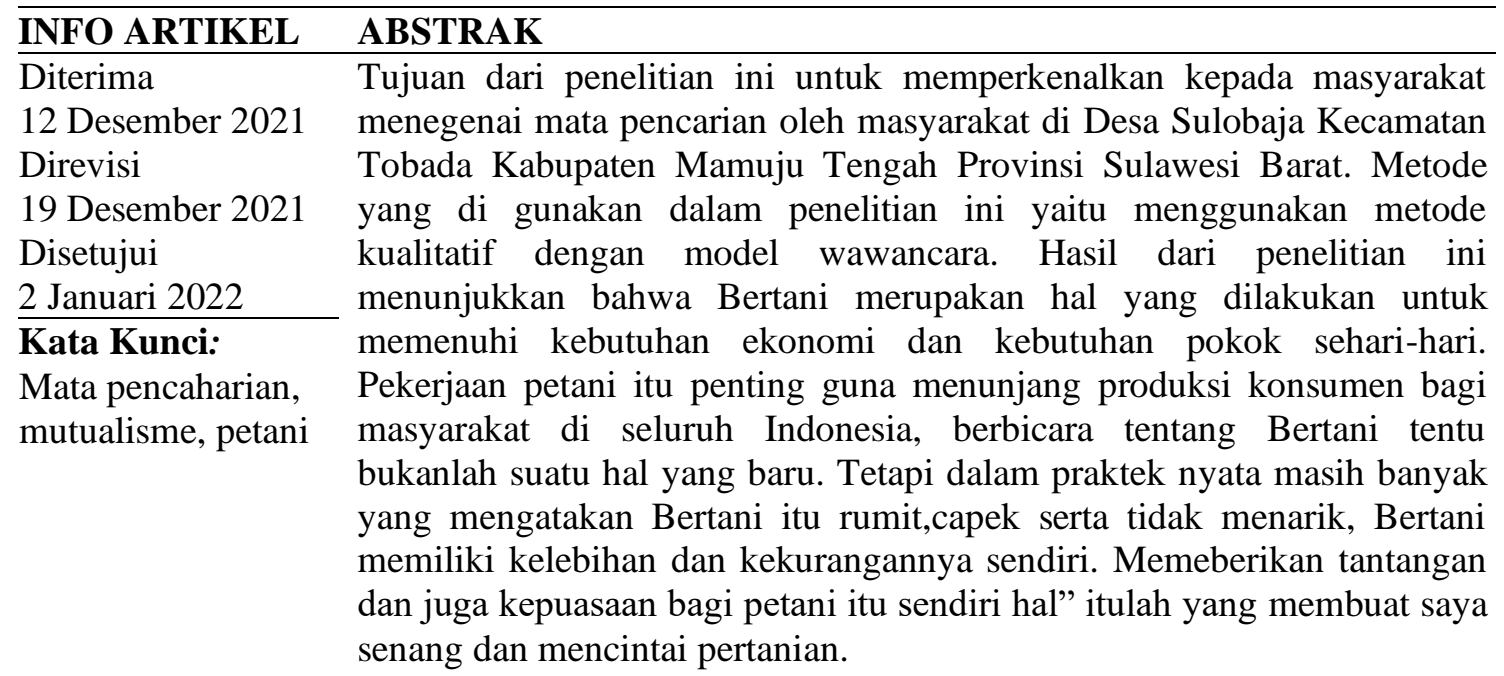

\section{ABSTRACT}

The purpose of thisstudy is to introduce to thr cominity about the livelihoods carried out by the cominity in sulobaja village, tobada districy, central mamuju regency, west Sulawesi province. The method used in this study is to use a qualitative method with an interview model. The results of this study indicate that farming is something that is done to meet economic need and basic daily needs. Farmer's work is important to support consumer prices for people throughout Indonesia, talking about farming is certainly not new. But in practice there are still many who say farming is complicated, tiring and unattractive. Farming has its

Keywords:

Livelihoods, own advantages and disadvantages, it provides challenges as well as mutualism, farmers satisfaction for the farmers themselves, that's what makes me happy and loves agriculture

\section{Pendahuluan}

Desa memiliki hak asal usul serta hak tradisional, sebagaimana dalam mengatur dan mengurus berbagai bentuk sehingga perlu dilindungi dan di berdayakan agar menjadi kuat, maju, mandiri dan demokratis (Suparman, 2014). Sehingga dapat menciptakan landasan yang kuat dalam melaksanakan pemerintahan dan pembangunan menuju masyarakat yang adil, makmur serta sejahtera. Sebagai lapisan yang terbawah dari struktur pemerintahan, aktivitas masyarakat di desa sulobaja sudah semestinya mendapatkan kesempatan untuk dapat mengembangkan potensi yang dimiliki (Lestari et al., 2019). Kebijakan pemerintah suatu pemberdayaan potensi desa dalam realitanya belum berjalan dengan maksimal

$\begin{array}{ll}\text { How to cite: } & \text { Nofani, Metildis (2022). Mata Pencarian Sebagai Mutualisme Masyarakat Petani Di Desa Sulobaja, } \\ & \text { Action Research Literate, 6(1). } \\ \text { E-ISSN: } & 2721-2769 \\ \text { Published by: } & \text { Ridwan Institute }\end{array}$


(Liwu \& Sasmito, 2019) salah satu faktor penyebabnya adalah aparatur desa sebagai fasilitator proses pembangunan desa belum siap mengimplementasikan undang- undang nomor 6 tahun 2014 pada pasal 1 ayat 1 menegaskan bahwa "Desa sebagai kesatuan masyarakat hukum yang memiliki batas wilayah yang berwenang untuk mengatur serta mengurus urusan pemerintahan" (Itang, 2017).

Dalam kehidupan manusia tidak terlepas dari kebutuhan untuk kelangsungan hidup, tentunya dengan adanya kebutuhan diperlukan mata pencaharian yang merupakan sumber kpenghasilan penghidupan masyarakat. Berdasarkan hasil penelitian di desa sulobaja bahwa di pedesaan ini mengalami peningkatan sumber pendapatan bagi masyarakat di pedesaan tersebut (Mardiyaningsih \& Dharmawan, 2010). Sumber pendapatan ini membantu masyarakat untuk memenuhi kebutuhannya, sebagaimana di hasilkan dari beberapa di

Oleh sebab itu berdasrkan latar belakang di atas peneliti mengangkat judul penelitian yaitu "Mata Pencarian Sebagai Mutualisme Masyarakat Petani di Desa Sulobaja".

\section{Metode Penelitian}

Dalam pandangan kita pakai perspektif metode penelitian kualitatif serta kuantatif (Sugiyono, 2017a), bagaimana metode penelitian pada dasarnya merupakan cara ilmiah untuk mendapatkan data dengan tujuan dan kegunaan tertentu. Berdasrkan hal tersebut terdapat empat kata kunci yang perlu di perhatikan yaitu cara ilmiah,, data tujuan dan kegunaaan. Dimana data yang disebut itu saat kita mengumpulkan data" apa saja yang kita dapat selama kita berada di desa sulobaja ataukegiatan apa yang kita dapat dan apa" saja yang kita ketahui mengenai peristiwa di desa sulobaja. Terdapat beberapa istilah pada kedua metode tersebut. Borg and gall (1989) metode kuantitatif dan kualitatif sering di pasangkan dengan nama metode yang tradisonal, dan metode baru, metode positivistic dan metode postpositivistik; metode scientific dan metode artistic, metode konfirmasi dan temuan; serta kuatitatif dan interpretif, jadi metode kualitatif sering di namakan metode tradisional, positifistik, scientific, dan metode discovery (Sugiyono, 2017b).

\section{Hasil dan Pembahasan}

Lahan pertanian merupakan pemersatu dalam sistem sosial pedesaan sekaligus sebagai landasan kehidupan, faktor produksi, kemakmuran dan tempat tinggal (Asriyanti Syarif et al., 2017). Dalam konteks ini wanita masih memegang peran penting dalam pengelolaan pertanian. Bank dunia menyebutkan bahwa banyak wnaita berusia antara 16-60 tahun beruang dan bekerja keras di sector pertanian untuk pemenuhan kebutuhan. Oleh karena itu umur serta jenis kelamin tidak menjadi daya pandang untuk suatu segi pekerjaan, karena hanya memerlukan usaha dan fisik yang kuat untuk menjamin suatu pekerjaan yang baik yaitu pertanian.

Di desa sulobaja bahasa yang di gunakan dalam kesehariannya yaitu bahasannya masing-masing Adapun juga mereka berkomunikasi dengan menggunakan bahasa keseharian seperti biasanya orangorang, karena di dalam desa ini terdapat beberapa suku yang berbeda" sehingga bahasannya pun yang di gunakan berbeda". di desa sulobaja ini terdapat sepanjang jalan kelapa sawit begitu luasnya kebun yang masyarakat Kelola sehingga kelapa sawit adalah kunci pertama mata pencariannya, setelah beberapa hari saya berkeliling jalan memantau apa saja yang masyarakat di sulobaja yang dimilikinya dan ternyata yang lebih saya tertarik pada kelapa sawit yang begitu sangat banyak dan begitu luasnya.

Transformasi adalah perubahan bentuk, dari satu bentuk ke bentuk yang lain 
(Sulistiyono \& Rindarjono, 2015). Dalam pengertian yang lebih luas, transformasi tidak hanya saja mencakup perubahan pada bentu luar (fisik), tetapi juga perubahan pada struktur ekonomi dan sosial budaya dalam suatu masyarakat yang dapat menjamin kelangsungan hidup suatu masyarakat. Setelah menelusurinya, ternyata penghasilan yang masyarakat di desa sulobaja dalam mata pencarian kelapa sawit bisa di bilang sangatlah luar biasa atau untuk mencukupi kebutuhan ekonominya. Dari minyak kelapa sawit ini sangatlah menghasilkan bahan pokok yang kaya akan manfaaatnya, berbagai manfaat yang kita ketahui sebagai industry makanan, sampai industry kosmetik. Bahkan juga limbahnya masih bisa kita manfaatkan untuk industry mebel, oleokimia hingga pakan ternak., Pentingnya kegunaan ini sebagai bahan pokok kehidupan sehari-hari. Agar para nelayan dapat mempertahankan penghasilan di tengah berbagai ancaman yang di alami sector perikanan dan sekaligus mengurangi kmiskinan di anatar merek, penting di lakukan upaya untuk menciptakan mata pencahrian tambahan bagi kelompok penduduk ini, yang di antara lain di peroleh melalui penciptaan mata pencarian alternatif.

Rumah tangga petani berusaha untuk memenuhi kebutuhan sehari-hari dengan melakukan aktivitas kerja di non pertanian. Namun juga tetap menjadi pekerja pada kegiatan pertanian terutama pada saat musim sibuk pada kegiatan usahataninya, adanya perubahan harga input atau output. Upah tenaga kerja, luas kepemilikan lahan rumah tangga diduga akan berpengaruh langsung pada perilaku ekonomi rumah tangga petani untuk menghasilkan pendapatan. Tentu dalam rumah tangga juga mempengaruhi pendapatan ekonomi jika tidak melakukan pekerjaan sedemikian baik, akan tetapi juga rumah tangga juga memberikan kita pandangan bahwa selain menjadi rumah tangga di samping itu juga mengahasilkan usaha pertanian atau suatau lahan
Tidak hanya itu juga mereka masih menggunakan alat teknologi seperti cangkul dan lain-lainnya, dengan itu pekerjaaan nya begitu cepat atau selesai. Dan ada juga beberapa masyarakat yang berjalan kaki menuju lahan kebun nya dan tidak menggunakan apa" seperti transportasi motor, mobil. Tetapi dengan begitu suatu hal yang sehat bagi rohani dan jasmani, Dengan adanya transportasi juga dapat mempermudah pekerjaan para petani yang ada di desa sulobaja, Dan dengan adanya teknologi yang sekarang juga ini dapat meringankan dan membantu para petani, Walaupun masih ada beberapa Sebagian yang masih pakai teknologi yang dulu berarti mereka masih mencintai teknologi di masa dulu. Ada beberapa kendaraan yang dibutuhkan pada saat itu mobil,dan motor.

Menurut (Muslimah \& Si, 2017) langkah-langkah yang perlu kita ketahui bahwa untuk mencegah terjadinya kerusakan pada lahan maka kita harus menjaga dan melestarikannya dengan baik, jika kita mengupayakannya dengan cara menanam pohon yang sangat bermanfaat bagi kita semua tekhusus bagi masyarakat yang ada di desa sulobaja. Kalau adanya terjadi perubahan cuaca iklim itu karena alam akan tetapi jika ada campur tangan dari manusia maka akan berdmpak dan merugikan kita sendiri atau masyarakat lain, kita lebih memaksimalkan sebagaimana kita menjaganya dengan sebaik mungkin.

Hal yang perlu kita hindari yaitu membakar sampah di hutan itu akan mengakibatkan buruk bagi kita semua, adanya pencemaran lingkungan ini yang menjadi hambatan untuk para petani dalam mengelola lahan atau kebunnya jadi kita lebih di haruskan untuk mencegahnya dari dari pada sudah terjadi dan merugikan masyarakat.Dan para petani juga tidak dapat mencari mata pencarian lagi jika adanya peristiwa tersebut ekonominya yang menurun 
sehingga tidak ada yang dapat mereka lakukan.

Sumber daya alam berupa kebun, akan bermanfaat bagi para petani dimana dia mengoptimalkan kinerjannya, sehingga menghasilkan upah yang begitu besar dalam mengelola kebun atau lahannya. Petani juga akan memanfaatkan suatu lahannya untuk mendapatkan keuntungan hanya saja jika dia tidak memanfaatkan sebaik mungkin maka akan terjadi kerusakan terhdap lahannya.

Kelapa sawit yang dari pemerintah untuk masyarakat petani di desa sulobaja Kelola untuk menjadikan salah satu mata pencariannya, maka dari itu mereka di namakan mutualisme antar petani karena sama-sama saling menguntungkan.

\section{Kesimpulan}

Indonesia yang kaya akan ragam budaya, termasuk di desa sulobaja ini memiliki penduduk yang agama,suku, ras yang berbeda". menciptakan keindahan alam yang begitu sangat indah dan masyrakat yang ada di suolobaja ini sangatlah memanfaatkan suatu lahan atau tanah yang kosong untuk menjadikan suatu keuntungan bagi mereka.

\section{BIBLIOGRAFI}

Asriyanti Syarif, S. P., Zainuddin, M., Hut, S., \& Hut, M. (2017). Inti Sari Sosiologi Pertanian (Vol. 1). Penerbit CV. Inti Mediatama. Google Scholar

Itang, I. (2017). Faktor Faktor Penyebab Kemiskinan. Tazkiya, 16(01), 1-30. Google Scholar

Lestari, E. Y., Sunarto, S., \& Wijayanti, T. (2019). Pendampingan Pada Masyarakat
Dalam Pengembangan Mata Pencaharian Melalui Pemberdayaan Komunitas Pemuda Desa Di Desa Lau Kecamatan Dawe Kabupaten Kudus. Jurnal Puruhita, 1(1), 47-53. Google Scholar

Liwu, A. S., \& Sasmito, C. (2019). Strategi Pemerintah Desa Dalam Pemberdayaan Kelompok Tani. JISIP: Jurnal Ilmu Sosial Dan Ilmu Politik, 8(4), 228-233. Google Scholar

Mardiyaningsih, D. I., \& Dharmawan, A. H. (2010). Dinamika Sistem Penghidupan Masyarakat Tani Tradisional Dan Modern Di Jawa Barat. Sodality: Jurnal Sosiologi Pedesaan, 4(1). Google Scholar

Muslimah, M. S., \& Si, S. (2017). Dampak Pencemaran Tanah Dan Langkah Pencegahan. J. Penelit. Agrisamudra, 2(1), 11-20. Google Scholar

Sugiyono. (2017a). Metode Penelitian Kuantitatif, Kualitatif, Dan $R \& D$. Alfabeta. Google Scholar

Sugiyono. (2017b). Metodepenelitian Kuantitatif, Kualitatif Dan R\&D. Bandung: PT Alfabet. In Sugiyono. (2017). Metodepenelitian Kuantitatif, Kualitatif Dan R\&D. Bandung: PT Alfabet. Google Scholar

Sulistiyono, D., \& Rindarjono, M. G. (2015). Transformasi Mata Pencaharian Dari Petani Ke Nelayan Di Pantai Depok Desa Parangtritis Kabupaten Bantul. Geoeco, 1(2). Google Scholar

Suparman, A. (2014). Desa Dan Hak-Hak Tradisional. Jurnal Wawasan Yuridika, 26(1), 464-470. Google Scholar

\section{Copyright holder :}

Metildis Nofani (2022).

First publication right :

Action Research Literate

This article is licensed under: 